\title{
Competitive Interference between an Endemic Cuban Green Anole (Anolis porcatus) and Invasive Tropical House Geckos (Hemidactylus mabouia)
}

\author{
Rafael Borroto-Páez ${ }^{1}$ and Denise Reyes Pérez ${ }^{2}$
}

1Sociedad Cubana de Zoología, AP 11900, La Habana, Cuba (borroto@yahoo.com)

${ }^{2}$ Instituto de Geografía Tropical, Calle F entre 11 y 13, Vedado, La Habana, Cuba.

C ompetition between species can occur where an introduced species occupies the same microhabitat, operates along the same temporal niche and utilizes the same resource(s) as resident species (Pianka 1973). Competition for food, refugia, perches, and resources can also change the behavioral or spatial ecology of natives and this has led to the widest array of impacts (e.g., Echternacht 1999; Suzuki and Nagoshi 1999; D’Amore et al. 2009b; Cole and Harris 2011; Kraus 2015).

In the classical definition of interference competition, interacting species incur only costs but no benefits. For instance, each consumer species suffers a reduction in individual growth rates because acts of interference divert time and energy from resource exploitation; in addition, interference can increase the risk of injury or death by predation (Case and Gilpin 1974; Schoener 1983; Vance 1984).

The rate at which non-native reptiles are being introduced around the world has increased in recent times (e.g., Kraus 2009). The resultant competition can affect native species, and evidence of such instances must be studied and understood (Case and Bolger 1991; Rodda and Fritts 1992; Losos et al. 1993; Case et al. 1992, 1994; Petren and Case 1998; Losos and Spiller 1999; Brown et al. 2002; Cole et al. 2005; Dufour et al. 2018). However, the paucity of evidence for competition as a causal or contributing mechanism for extinction could be because interactions between invasive and

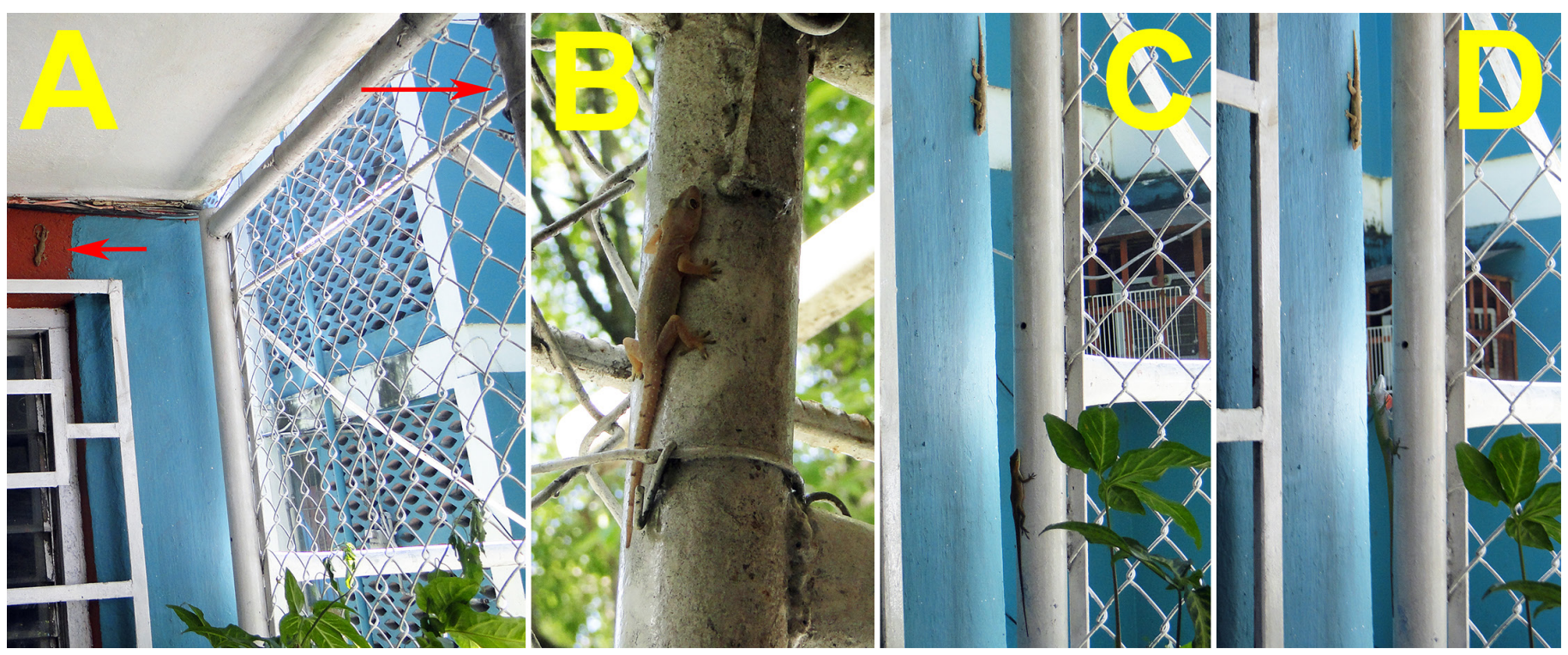

Fig. 1. (A) Initial position of two Tropical House Geckos (Hemidactylus mabouia $=H m$ ) on a wall (left arrow) and a fence post (right arrow). (B) Initial position of $H m$ on a fence post. (C) A Cuban Green Anole (Anolis porcatus = Ap) approaches Hm. (D) Ap displays to $H m$. 


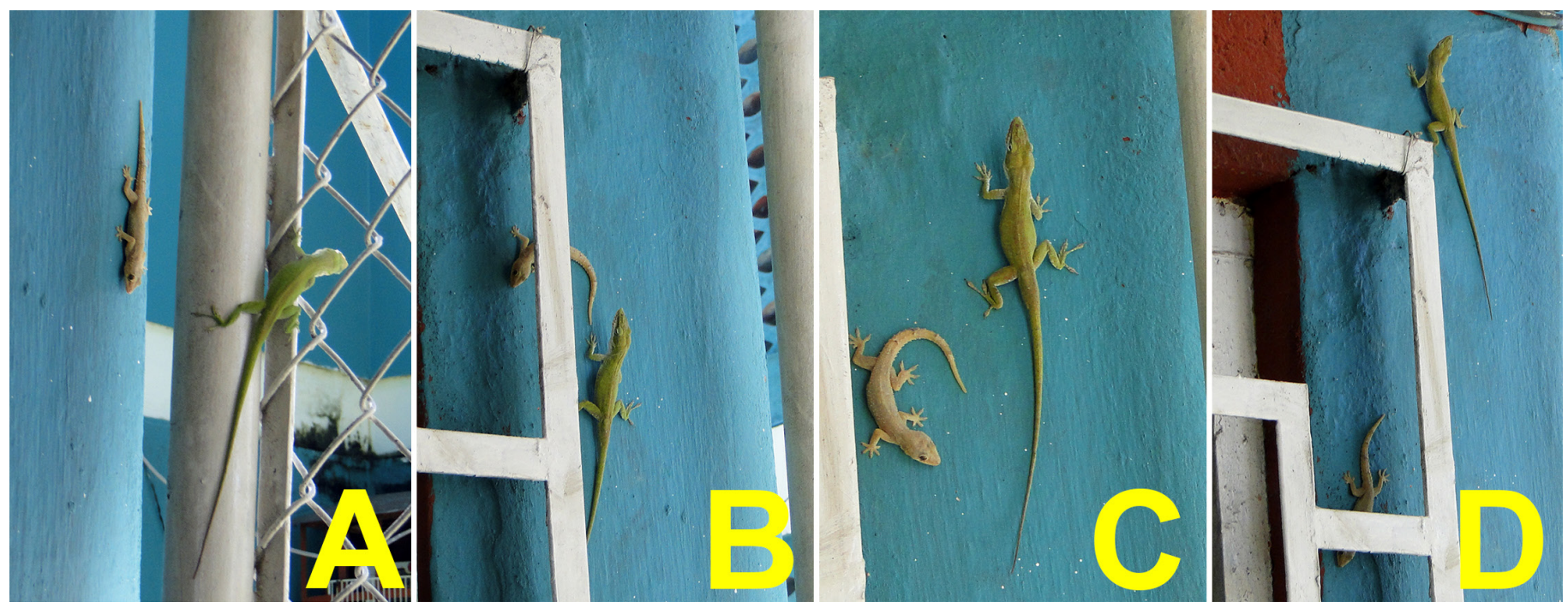

Fig. 2. (A) The Cuban Green Anole (Anolis porcatus = Ap) continues the display and approaches the Tropical House Gecko (Hemidactylus mabouia = Hm). (B) $A p$ jumps to the wall close to $H m$ and they circle one another. (C and D) $A p$ and $H m$ continue circling.

native competitors can occur without obvious direct negative effects, rendering long-term deleterious effects difficult to measure (Crawley 1986; Petren and Case 1996).

Factors proposed to explain why animals do or do not defend territories range from predation risk (Stamps 1977, 1983; Myers 1980) to energetic economics (Davies and Houston 1984). The energetics of competition and the cost of display behavior to avoid or reject a possible competitor are other unknown mechanisms. Brown (1964) first clearly formulated an economic cost-benefit approach indicating that animals living under energetic constraints should defend territories when the benefit (exclusive food use) exceeds the cost (defense and risks) and the resulting net benefit exceeds that of non-territorial behavior.

Anoles display a variety of competitive behaviors that include dewlap extension and retraction combined with head and other body movements in various species-specific patterns; although used as predator deterrents, such behaviors also serve to facilitate intraspecific communication during mating and when maintaining territories (Jenssen 1977; Leal and Rodriguez-Robles 1997; Nicholson et al 2007).

The Cuban Green Anole (Anolis porcatus) is endemic, abundant, and widely distributed across the Cuban Archipelago where it is frequently associated closely with

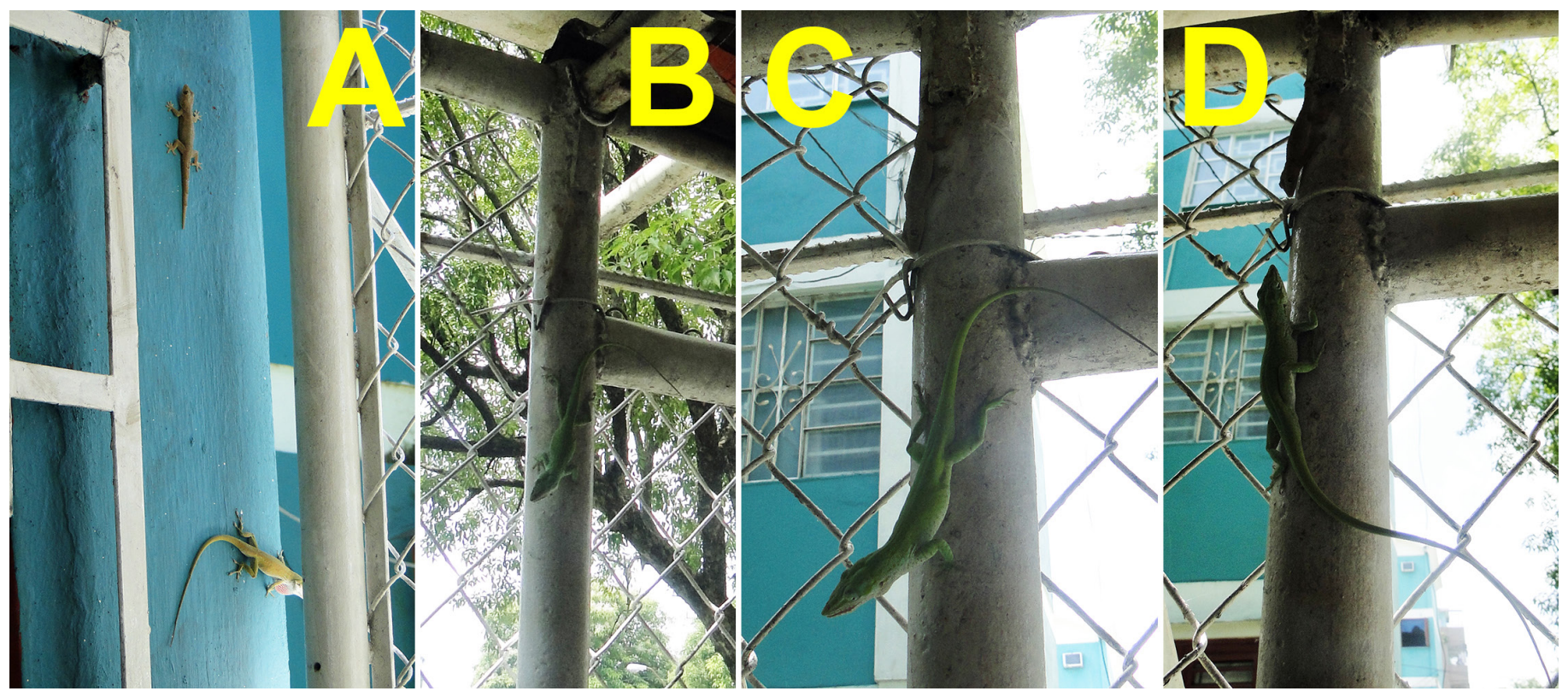

Fig. 3. (A) The Tropical House Gecko (Hemidactylus mabouia $=H m$ ) moves up and the Cuban Green Anole $($ Anolis porcatus $=$ Ap) moves down before jumping back onto the fence. (B) $A p$ confronts the other $H m$ on the fence. (C) $A p$ displays in close proximity to $H m$. (D) $A p$ turns face-to-face with $H m$. 


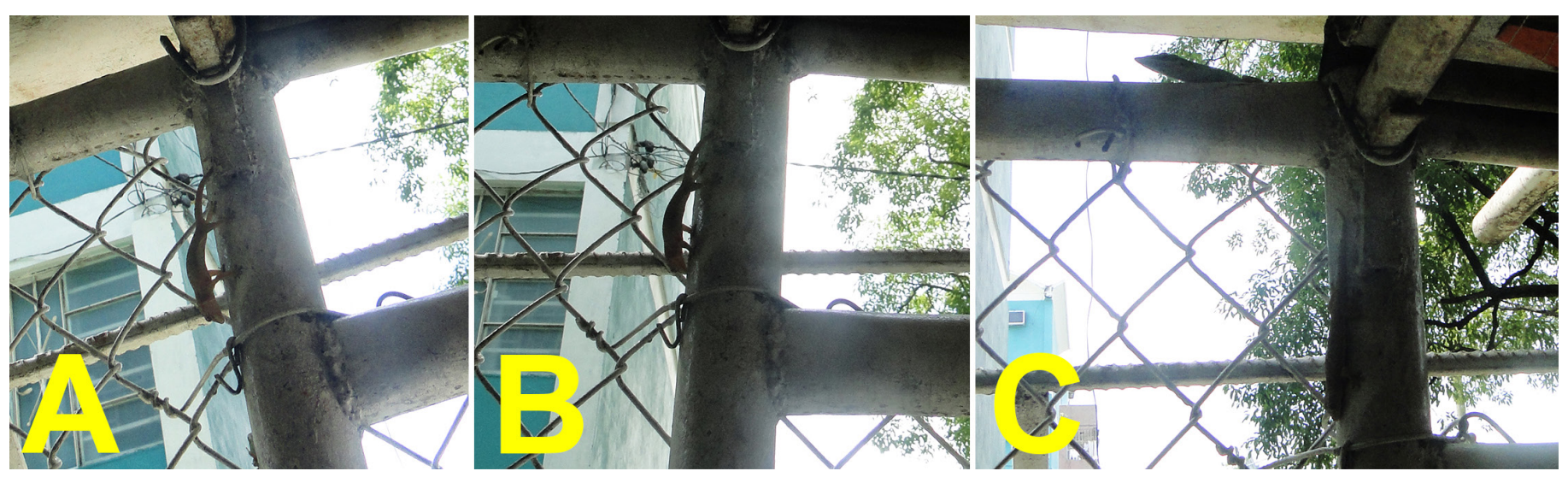

Fig. 4. (A) The Tropical House Gecko (Hemidactylus mabouia $=H m$ ) assumes an aggressive posture. (B) Hm maintains the aggressive posture in close proximity to the Cuban Green Anole (Anolis porcatus $=A p)$. (C) Ap retreats.

humans (e.g., Schwartz and Henderson 1991; Henderson and Powell 2009; Rodriguez-Schettino et al. 2013). The Tropical House Gecko (Hemidactylus mabouia), often called a "Woodslave" on English-speaking West Indian islands, was likely introduced to the region in concert with the slave trade during colonial times. It is now ubiquitous in Cuba, most frequently functioning as a human commensal (Borroto-Páez et al. 2013). Although largely nocturnal (e.g., Henderson and Powell 2009), individuals are sometimes active by day. Although the Woodslave has a long history in the Antilles, very little information documents competitive interactions and potential effects on native species.

During the morning of 7 April 2018, in Vibora Town, Ciudad Habana, we observed two Hemidactylus mabouia that were diurnally active in a residential yard. Geckos are relatively abundant in the apartments of the building (surveys having documented 2-3 individuals/apartment). One gecko was on the facade of the ground floor of the building and the other was about a meter away on one of the metal posts of a chain-link fence (Figs. 1A-B). Both were separated at a height of about 2 $\mathrm{m}$. By day, the fence usually is occupied by Anolis porcatus. When a resident anole noted the presence of the gecko on the wall at about $0930 \mathrm{~h}$, it moved to confront it (Figs. 1C-2A), displaying from a fence post (Fig. 1D) and the wall (Fig. 3A). Shortly thereafter, the anole jumped to the wall near to the gecko and approached it very closely. The two lizards circled one another for a few minutes (Figs. 2B-3A). When the anole moved higher on the wall, the gecko move to an adjacent wall and hid in a crack. The anole then jumped onto the fence and remained motionless until, at about $1120 \mathrm{~h}$ and an ambient temperature of $32^{\circ} \mathrm{C}$, it noticed the other gecko and moved to confront it. The gecko responded to the anole that approached while displaying (Figs. 3B-D) by assuming a defensive position (Figs. 4A-B) that was maintained until the anole moved away (Fig. 4C). Both lizards remained separated until about $1200 \mathrm{~h}$ when the second gecko disappeared without us having observed it.
The entire sequence clearly demonstrates an example of competitive interference. For more than $2 \mathrm{~h}$, the anole confronted and attempted to expel the house geckos from its territory. The movements, confrontations, and displays certainly came at a high energetic cost.

Few published references have documented interactions between introduced House Geckos and native species in Cuba and throughout the Caribbean. Not all were at the expense of the native species. For example, Powell and Henderson (1992) described Anguilla Bank Tree Anoles (Anolis gingivinus) displacing Tropical House Geckos (H. mabouia) at artificial night lights on St. Maarten and Owen and Perry (2005) described a Tropical House Gecko (H. mabouia) being eaten by a Puerto Rican Crested Anole (A. cristatellus) in the British Virgin Islands. Others, like the event illustrated in Fig. 1, came at a cost to the native species. Powell (2003) noted that introduced Common House Geckos ( $H$. frenatus) appeared to be displacing native Honduran Leaf-toed Geckos (Phyllodactylus palmeus) on Utila in the Honduran Bay Islands. R. Montes Espín (pers. comm.) reported predation on an anole by a Tropical House Gecko (H. mabouia) in Cuba. In addition, we observed an interaction similar to that described herein between a Cuban Blue Anole (A. allisoni) and a Tropical House Gecko (H. mabouia) in Corralillo, in central Cuba, also during the day and with displays and territorial defense by both species - but of such short duration that we were unable to document the event with photographs. However, these few reports speak to the possibility that interactions between Hemidactylus geckos and native species could be more common than has been recorded, especially when both parties are functioning as human commensals.

\section{Acknowledgements}

We thank Boris A. Fabres, Environmental Protection in the Caribbean (EPIC), for reviewing an early version of this manuscript and providing useful suggestions that improved it. 


\section{Literature Cited}

Borroto-Páez, R., R. Alonso Bosch, B.A. Fabres, and O. Alvarez García. 2015. Introduced amphibians and reptiles in the Cuban Archipelago. Herpetological Conservation and Biology 10: 985-1012.

Brown, J.L. 1964. The evolution of diversity in avian territorial systems. Wilson Bulletin 76: 160-169.

Brown, S.G., R. Lebrun, J. Yamasaki, and D. Ishii-Thoene. 2002. Indirect competition between a resident unisexual and an invading bisexual gecko. Behaviour 139: 1161-1173.

Case, T.J. and D.T. Bolger. 1991. The role of introduced species in shaping the distribution and abundance of island reptiles. Evolutionary Ecology 5: 272-290.

Case, T.J. and M.E. Gilpin. 1974. Interference competition and niche theory. Proceedings of the National Academy of Sciences of the United States of America 71: 3073-3077.

Case, T.J., D.T. Bolger, and A.D. Richman. 1992. Reptilian extinctions: The last ten thousand years, pp. 91-125. In: P.L. Fiedler and S.K. Jain (eds.), Conservation Biology: The Theory and Practice of Conservation, Preservation, and Management. Chapman \& Hall, New York.

Case, T.J., D.T. Bolger, and K. Petren. 1994. Invasions and competitive displacement among house geckos in the tropical Pacific. Ecology 75: 464-477.

Cole, N.C. and S. Harris. 2011. Environmentally-induced shifts in behavior intensify indirect competition by an invasive gecko in Mauritius. Biological Invasions 13: 2063-2075.

Cole, N.C., C.G. Jones, and S. Harris. 2005. The need for enemy-free space: The impact of an invasive gecko on island endemics. Biological Conservation 125: $467-474$

Crawley, M.J. 1986. The population biology of invaders. Philosophical Transactions of the Royal Society of London Series B-Biological Sciences 314: 711-731.

Dame, E. and K. Petren. 2006. Behavioural mechanisms of invasion and displacement in Pacific island geckos (Hemidactylus). Animal Behaviour 71: 11651173 .

D’Amore, A., E. Kirby, and V. Hemingway. 2009. Reproductive interference by an invasive species: An evolutionary trap? Herpetological Conservation and Biology 4: 325-330.

Davies, N.B. and A.I. Houston. 1984. Territory economics, pp. 148-169. In: J.R. Krebs and N.B. Davies (eds.), Behavioural Ecology. An Evolutionary Approach. 2nd Revised Edition. Sinauer Associates Inc., Sunderland, Massachusetts.

Dufour, C.M.S, A. Herrel, and J.B. Losos. 2018. The effect of recent competition between the native Anolis oculatus and the invasive $A$. cristatellus on display behavior. PeerJ 6: e4888.

Echternacht, A.C. 1999. Possible causes for the rapid decline in population density of green anoles, Anolis carolinensis (Sauria: Polychrotidae) following invasion by the brown anole, Anolis sagrei, in the southeastern United States. Anolis Newsletter 5: 22-27.

Henderson, R.W. and R. Powell. 2009. Natural History of West Indian Reptiles and Amphibians. University Press of Florida, Gainesville.

Jenssen, T.A. 1977. Evolution of anoline lizard display behavior. American Zoologist 17: 203-215.

Kraus, F. 2009. Alien Reptiles and Amphibians: A Scientific Compendium and
Analysis. Invading Nature: Springer Series in Invasion Biology 4. Springer, Dordrecht, The Netherlands.

Kraus, F. 2015. Impacts from Invasive Reptiles and Amphibians. Annual Review of Ecology, Evolution, and Systematics 46: 75-97.

Leal, M. and J.A. Rodríguez-Robles. 1997. Anti-predator responses of the Puerto Rican Giant Anole, Anolis cuvieri (Sauria: Polychrotidae). Biotropica 29: 372-375.

Losos, J.B. and D.A. Spiller. 1999. Differential colonization success and asymmetrical interactions between two lizard species. Ecology 80: 252-258.

Losos, J.B., J.C. Marks, and T.W. Schoener. 1993. Habitat use and ecological interactions of an introduced and a native species of Anolis lizard on Grand Cayman, with a review of the outcomes of anole introductions. Oecologia 95: 525-532.

Myers. J.P. 1980. Territoriality and flocking by Buff-breasted Sandpipers: Variations in non-breeding dispersion. Condor 82: 241-250.

Nicholson, K.E., L.J. Harmon, and J.B. Losos. 2007. Evolution of Anolis lizard dewlap diversity. PLoS ONE 2: e274.

Owen, J. and G. Perry. 2005. Anolis cristatellus wileyae (Virgin Islands Crested Anole). Saurophagy. Herpetological Review 36: 444.

Petren, K. and T.J. Case. 1996. An experimental demonstration of exploitation competition in an ongoing invasion. Ecology 77: 118-132.

Petren, K. and T.J. Case. 1998. Habitat structure determines competition intensity and invasion success in gecko lizards. Proceedings of the National Academy of Sciences of the United States of America 95: 11739-11744.

Pianka, E.R. 1973. The structure of lizard communities. Annual Review of Ecology and Systematics 4: 53-74.

Powell, R. 2003. Species profile: Utila's reptiles. Iguana 10: 36-38.

Powell, R. and R.W. Henderson. 1992. Anolis gingivinus. Nocturnal behavior. Herpetological Review 23: 117.

Rodda, G.H. and T.H. Fritts. 1992. The impact of the introduction of the colubrid snake Boiga irregularis on Guam's lizards. Journal of Herpetology 26: 166-174.

Rodríguez Schettino, L., C.A. Mancina, and V. Rivalta. 2013. Reptiles of Cuba: Checklist and geographic distributions. Smithsonian Herpetological Information Service 144: 1-96.

Schoener, T.W. 1983. Field experiments on interspecific competition. American Naturalist 122: 240-285.

Schwartz, A. and R.W. Henderson. 1991. Amphibians and Reptiles of the West Indies: Descriptions, Distributions, and Natural History. University of Florida Press, Gainesville.

Stamps, J.A. 1977. The relationship between resource competition, risk, and aggression in a tropical territorial lizard. Ecology 58: 349-358.

Suzuki, A. and M. Nagoshi. 1999. Habitat utilizations of the native lizard, Cryptoblepharus boutonii nigropunctatus, in areas with and without the introduced lizard, Anolis carolinensis, on Hahajima, the Ogasawara Islands, Japan, pp. 155-68. In: H. Ota (ed.), Tropical Island Herpetofauna: Origin, Current Diversity, and Conservation. Elsevier, Amsterdam, The Netherlands.

Vance, R.R. 1984 Interference competition and the coexistence of two competitors on a single limiting resource. Ecology 65: 1349-1357. 